\title{
Estudo da influência de cimentos na fluência em concretos para a construção civil
}

\section{(Study of the influence of cements on creep in concretes used in civil construction)}

\author{
M. A. Coimbra, W. Libardi, M. R. Morelli \\ Departamento de Engenharia de Materiais - DEMa \\ Universidade Federal de S. Carlos - UFSCar \\ Rod. Washington Luiz, km 235, S. Carlos, SP 13565-905
}

\begin{abstract}
Resumo
O objetivo deste trabalho consistiu em um estudo da influência de dois tipos diferentes de cimento Portland na propriedade fluência em concretos, em equipamento específico, uma propriedade viscoelástica que se origina na pasta endurecida de cimento e presume-se que esteja relacionada principalmente à remoção da água adsorvida. As causas da fluência no concreto são complexas. Normalmente concorda-se que, além dos movimentos da umidade, há outras causas que contribuem para o fenômeno de fluência. A não-linearidade da relação tensão-deformação no concreto, especialmente em níveis de tensão maiores do que 30 a 40 por cento da última tensão, mostra claramente a contribuição das microfissuras da zona de transição à fluência, um fenômeno bem conhecido nas engenharias civil e materiais. A técnica de formação de uma microestrutura controlada vem sendo apontada como uma promissora alternativa para o entendimento do mecanismo de fluência. A avaliação do estudo bibliográfico procurou apontar os principais parâmetros e variáveis envolvidas nesta propriedade, de maneira a incentivar o seu desenvolvimento e pesquisa.
\end{abstract}

Palavras-chave: cimento Portland, concreto, propriedades, fluência.

\begin{abstract}
This paper reports on a study of the influence of two different types of Portland cement on the creep property of concretes, a viscous elastic property originating in the hardened cement paste and presumably related mainly to the removal of adsorbed water. The causes of creep in concrete are complex. It is a generally accepted fact that, in addition to the movement of moisture, other causes contribute to the creep phenomenon. The nonlinearity of the stress-deformation relation in concrete, especially at levels of stress exceeding 30 to 40 per cent of the ultimate stress, clearly indicates the contribution of transition zone microcracks to creep, a phenomenon well known in civil and materials engineering. The controlled microstructure formation technique has been indicated as a promising alternative for understanding the creep mechanism. This study included a review of the literature to identify the main parameters and variables involved in the creep property, aiming to encourage development and research on this subject.
\end{abstract}

Keywords: Portland cement, concrete, properties, creep.

\section{INTRODUÇÃO}

As variações volumétricas do concreto podem ocorrer quando o mesmo ainda está fresco ou após o seu endurecimento. Observa-se que o volume do concreto endurecido é menor que o volume do concreto fresco, devido à perda parcial do ar incorporado e da água. Com isso, pode-se dizer que o concreto se apresenta como um material sólido, contendo no seu interior poros capilares, tomados em parte por água e em parte por ar.

A existência desses poros é inevitável, porque o volume de água empregado no preparo do concreto, a fim de tornálo moldável, é sempre maior do que a quantidade necessária para as reações químicas de pega. Desta forma, durante o endurecimento este excesso de água permanece no interior do concreto, dando lugar ao aparecimento de uma rede capilar de poros muito finos. Logo após o endurecimento, estes poros estão saturados; posteriormente, quando a cura se finalizar, parte do excesso de água irá se evaporar, surgindo então fenômenos capilares, responsáveis por determinadas deformações do concreto. A deformação lenta do concreto ou fluência possui um comportamento interno similar a estes fenômenos capilares.

A fluência ocorre em todos os tipos de solicitação, isto é: na força normal, força cortante, flexão e na torção. Com mais freqüência, devem ser consideradas as solicitações de compressão, pois, além de esta ser a mais importante, não existem dados suficientes para considerar as demais.

O concreto de cimento Portland é atualmente o material 
manufaturado mais utilizado do mundo. Julgando pelas tendências mundiais o futuro do concreto parece ser ainda mais promissor, porque para a maioria das aplicações ele oferece propriedades adequadas a um baixo custo combinado com os benefícios ecológicos e de economia de energia. É, portanto desejável que se saiba mais sobre o concreto do que qualquer outro material de construção.

Existem várias dificuldades ao se pretender dar um tratamento científico sobre o concreto. Primeiramente, apesar da aparente simplicidade do concreto, ele tem uma estrutura altamente complexa; portanto as relações estrutura-propriedade que são geralmente tão úteis para o entendimento e controle das propriedades dos materiais não podem ser facilmente aplicáveis. O concreto contém uma distribuição heterogênea de muitos componentes sólidos, assim como vazios de várias formas e tamanhos que podem estar completa ou parcialmente cheios de solução alcalina. Alguns métodos analíticos da ciência dos materiais e da mecânica dos sólidos que funcionam muito bem com materiais manufaturados relativamente homogêneos e muito menos complexos como o aço, os plásticos e as cerâmicas, não se mostram muito efetivos com o concreto.

Em segundo lugar, comparado com outros materiais a estrutura do concreto não é uma propriedade estática. Isto é porque dois dos três componentes da estrutura - a pasta de cimento e a zona de transição entre o agregado e a pasta de cimento - continuam a se modificar com o tempo. Neste aspecto, o concreto se assemelha à madeira e outros sistemas vivos.

De fato, a palavra concreta vem do latim "concretes", que significa crescer. A resistência e outras propriedades do concreto dependem dos produtos de hidratação do cimento, que continuam a se formar por muitos anos. Embora os produtos sejam relativamente insolúveis podem se dissolver vagarosamente e se recristalizar em ambientes úmidos, permitindo que o concreto sele suas microfissuras.

Em terceiro lugar, ao contrário de outros materiais que são entregues em sua forma final, o concreto é freqüentemente manufaturado no canteiro de obras.

O concreto já há algum tempo é considerado o material mais amplamente utilizado no mundo e o seu desempenho (físico e mecânico) aumenta continuamente. Ao mesmo tempo, é um começo da possibilidade de determinar precisamente os parâmetros da composição e produção que melhor encontra a especificação do material, isto é, um conjunto de propriedades funcionais fixadas ou escolhidas para um determinado projeto. A industria indubitavelmente fará mais e mais uso de seu domínio [1].

Neste contexto, modelos baseados em simulações aumentam seu papel, não somente para os últimos passos dados pela indústria da construção como: cálculos das quantidades de aços, análises dos estados limites de tensão, entre outros, mas também como uma ferramenta para comparação para diferentes soluções nas estruturas dos materiais. Esta otimização que leva a um "aumento de soluções” emprega uma quantidade de ferramentas com a possibilidade de um projeto mais rápido e eficiente [2].

A combinação de aço e concreto tem feito deste um dos principais e mais popular material do mundo. No entanto, a necessidade de conhecimento sobre o desempenho do concreto ao longo do tempo e o rigor dos impactos ambientais tem causado sérios problemas.

Existem diferentes causas de deterioração das estruturas de concreto, assim como corrosão das barras de reforço devido a carbonatação ou entrada do cloro, ação esquentaesfria, ataque de sulfatos, ação de agregados álcalis, entre outros. O uso de materiais ou planejamentos errados, números inadequados, controle insuficiente da qualidade, cura inadequada, e outros motivos, têm reduzido à vida útil das estruturas ou tem aumentado demasiadamente a manutenção, aumentando os custos. Como resultado, mais e mais normas restritivas são introduzidas em vários códigos de numeração prática com os projetos e construção destas estruturas. Isto agora é conhecido através de vários sistemas de normalização como: American Society for Testing and Materials, Associação Brasileira de Normas Técnicas, European Standard on Concrete, entre outras.

O impacto econômico do problema da durabilidade conduz a uma pesquisa extensiva de duas décadas e tem iniciado os caminhos para a produção de melhores e mais duráveis concretos ou estruturas de concreto reforçadas. Muitos métodos de ensaios e desenvolvimento de técnicas têm mostrado através dos anos uma taxação no tempo de vida residual de estruturas existentes.

As propriedades da engenharia para o concreto, assim como resistência, durabilidade, retração, permeabilidade e fluência são diretamente influenciadas e controladas pelo número, tipo tamanho e distribuição de poros presentes na pasta de cimento, no agregado e na interface entre os dois. Por exemplo, elasticidade e fluência do concreto são afetadas pelo volume total de poros considerando que a resistência é influenciada pela distribuição do tamanho de poros [3, 4].

Um bom tempo tem decorrido desde a primeira observação da retração do concreto no século passado e a descoberta da fluência em 1907 por Hatt [5]. Desde então, muitas pesquisas têm sido dedicadas para este complexo problema.

No entanto, os fenômenos da fluência e retração tem muito a que serem conhecidas para serem totalmente entendidas. Este tema tem sido objeto de estudo das melhores mentes no campo da pesquisa em cimento e concreto e ciência dos materiais, ao longo dos últimos 90 anos, tais como: Glanville, Dischinger, Troxell [6], Picket, McHenry, L'Hermite [7], Powers, Hansen and Mattock [8], Rüsch, Neville [9], Trost, Dilger, Wittman, Hilsdorf, Müller, Huet, Carol, [10].

Acredita-se que espaços capilares maiores do que $50 \mathrm{~nm}$ (macroporos) são prejudiciais à resistência e impermeabilidade, e considerando vazios menores do que 50 nm (microporos) são mais danosos à retração por secagem e fluência [11]. A água existente em poros maiores do que $50 \mathrm{~nm}$ comporta-se como água livre e possui um papel importante na durabilidade do concreto. 
Assim, pode-se concluir que é difícil fazer um bom concreto. Um "mau" concreto - muitas vezes uma substância com consistência inadequada, endurecendo em uma massa não homogênea com falhas - é feita simplesmente misturando-se cimento, agregados e água. Surpreendentemente, os ingredientes de um "bom" concreto são exatamente os mesmos, e é apenas o conhecimento, com o apoio do entendimento, o responsável pela diferença.

O concreto é um material composto que consiste essencialmente de um meio contínuo aglomerante, dentro do qual estão mergulhadas partículas ou fragmentos de agregados. No concreto de cimento hidráulico, o meio aglomerante é formado por uma mistura de cimento hidráulico e água.

Assim, basicamente os componentes que compõem o concreto são: a) cimento Portland; b) agregados: miúdo - areia e graúdo - pedra ou brita; e c) água.

Existe uma proporcionalidade direta entre a fluência e a tensão aplicada [12], exceção feita para elementos carregados a idades muito pequenas. Não existe um limite inferior da proporcionalidade porque o concreto é passível de fluência, mesmo sob tensões muito pequenas. O limite superior de proporcionalidade é alcançado quando surgem no concreto microfissuras sérias; isso ocorre a uma tensão expressa como fração da resistência, menor para materiais mais heterogêneos. Assim, essa fração é, para o concreto, usualmente entre 0,4 e 0,6 , mas ocasionalmente pode atingir valores tão baixos como 0,3 , ou altos até 0,75 ; este último se aplica a concretos de alta resistência [13]. Em argamassas, o limite está no intervalo entre 0,80 a 0,85 .

Aparentemente, pode-se concluir com segurança que, dentro do intervalo das tensões nas estruturas em serviço, é válida a proporcionalidade entre fluência e a tensão, e as expressões da fluência partem dessa hipótese. A recuperação da fluência também é proporcional à tensão aplicada previamente [14].

O tipo de cimento tem efeito sobre a fluência através da influência sobre a resistência do concreto no momento da aplicação da carga. Por esse motivo, qualquer comparação de concretos feitos com diferentes tipos de cimento deveria levar em conta a influência do tipo de cimento sobre a resistência no momento da aplicação da carga. Sob este aspecto, tanto os cimentos Portland dos diversos tipos como os cimentos aluminosos resultam sensivelmente valores iguais de fluência $[15,16]$, mas a velocidade de aumento da resistência tem algum efeito.

Um dos fatores externos mais importantes que atuam sobre a fluência é a umidade relativa do ar que envolve o concreto. Em linhas gerias, pode-se dizer que, para um mesmo concreto, quanto menor a umidade relativa, maior a fluência. Isso é ilustrado na Fig. 1 para peças curadas a umidade relativa $100 \%$ e depois carregadas e expostas a diversas umidades. Esse tratamento resulta retrações muito variáveis nas diversas peças durante os primeiros estágios após a aplicação da carga mantida [17].
As velocidades de fluência durante esse período variaram de modo correspondente, mas a idades posteriores, as velocidades eram aparentemente pouco diferentes. Assim, a secagem da peça enquanto carregada aumenta a fluência, isto é, induz a fluência adicional por secagem. A fluência da umidade relativa é muito menor, ou nenhuma, no caso de elementos que tenham atingido equilíbrio higroscópico com o meio antes da aplicação da carga [18]. Assim, na realidade, não é a umidade relativa que tem efeito sobre a fluência, mas o processo de secagem, isto é, a ocorrência da fluência por secagem.

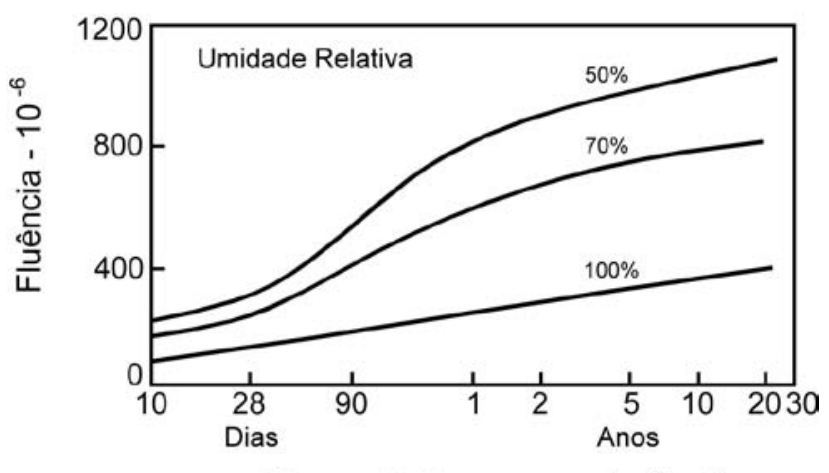

Tempo de Carregamento (Log)

Figura 1: Fluência de concreto curado durante 28 dias e depois carregado e conservado a diferentes umidades relativas.

[Figure 1: Creep concrete after 28 days of aging, loaded and maintained at different relative humidity.]

A fluência por secagem pode ser relacionada, ou por ela influenciada, com a tensão de tração induzida na parte externa de elementos de concreto pela retração restringida e pela fissuração resultante [19].

A tensão de compressão que se origina da aplicação de uma carga de compressão anula essa fissuração [20]. Em conseqüência, a retração efetiva de um elemento é maior do que a retração medida de um elemento que tenha sofrido uma fissuração superficial. Portanto, a abordagem que considera aditivas a fluência e a retração adota um valor muito pequeno de retração: a diferença entre esse valor que se admite para a retração e o valor real em um elemento carregado representa a fluência por secagem.

\section{MATERIAIS E MÉTODOS}

\section{Difratometria de raios $X$}

Pós obtidos por desaglomeração em almofariz foram analisados através de difratometria de raios $\mathrm{X}$. Utilizou-se um equipamento Siemens diffractometer (Rigaku Co., Japan) modelo D5000, radiação $\mathrm{Cu} k \alpha$. As condições de operação foram: $40 \mathrm{kV}$ na aceleração da voltagem, corrente de $40 \mathrm{~mA}, 2 \theta$ de 10 a $80^{\circ}$ e varredura de $2 \% \mathrm{~min}$. 


\section{Distribuição do tamanho de partículas}

A distribuição do tamanho de partículas dos pós foi obtida através da técnica baseada na sedimentação de partículas. Essa técnica consiste na determinação da fração de partículas em um plano de determinada profundidade em uma suspensão homogênea diluída $(<4 \%$ vol $)$.

\section{Resistência mecânica à compressão}

A resistência à compressão foi analisada através de duas máquinas de ensaios: uma do tipo Instron $5500 \mathrm{R}$ Reversible Load Cell (25.000 kg), e outra máquina de ensaios A. J. Amsler \& Co, Suissa 66/64 (100.000 kg). Para as composições cilíndricas de $5 \times 10 \mathrm{~cm}^{2}$ e $10 \times 20 \mathrm{~cm}^{2}$ foram utilizadas uma amostragem de 4 corpos-de-prova na Instron 5500 [21].

\section{Fluência}

A propriedade fluência foi analisada em equipamento específico para medição em argamassas e concretos, que foi idealizado e projetado pelos autores segundo a normalização vigente, utilizando-se como extensômetros relógios comparadores e apalpadores lineares ópticos [22].

\section{RESULTADOS E DISCUSSÃO}

\section{Cimento Portland}

A partir do conhecimento das reatividades relativas e dos seus produtos de hidratação, é possível produzir cimentos com características especiais como os de alta resistência inicial e outros.

Desse modo, foram analisados os cimentos Portland $C P$ II Z $32 R S$ da marca Itaú (tendo como composição básica: clínquer Portland, gesso, filler calcário e material pozolânico, segundo o fabricante) e o cimento Portland CP II E $32 \mathrm{RS}$, também da marca Itaú, (tendo como composição básica: clínquer Portland, gesso, filler calcário e material escória de alto forno granulada) [23].

O cimento Portland Tipo II é utilizado para uso geral, especialmente quando se deseja moderada resistência ao sulfato ou moderado calor de hidratação. As fases necessárias para que isto ocorra são: $\mathrm{C}_{3} \mathrm{~A}\left(3 \mathrm{CaO} \cdot \mathrm{Al}_{2} \mathrm{O}_{3}\right)$ e $\mathrm{C}_{3} \mathrm{~S}(3 \mathrm{CaO}$. $\mathrm{SiO}_{2}$ ou também chamada de alita).

A norma limita a quantidade de $\mathrm{C}_{3} \mathrm{~A}$ no cimento no máximo em $8 \%$. Como se vê através do difratograma da Fig. 2 existe uma predominância das fases $\mathrm{C}_{3} \mathrm{~S}\left(3 \mathrm{CaO} . \mathrm{SiO}_{2}\right)$ e $\mathrm{C}_{2} \mathrm{~S}$ ( $2 \mathrm{CaO} . \mathrm{SiO}_{2}$ ou também chamada de belita), demonstrando que se confirma uma das fases, a qual a literatura reporta $\left(\mathrm{C}_{3} \mathrm{~S}\right)$, mas não confirma a outra $\left(\mathrm{C}_{3} \mathrm{~A}\right)$, no nível de detecção dos raios $\mathrm{X}$, tanto para o cimento Portland do tipo $\mathbf{Z}$ quanto para o do tipo $\mathbf{E}$.

O cimento Portland do tipo $\mathbf{Z}$ - como o utilizado - caracteriza-se por ser pozolânico. As pozolanas podem ser definidas como "materiais silicosos ou sílico-aluminosos",

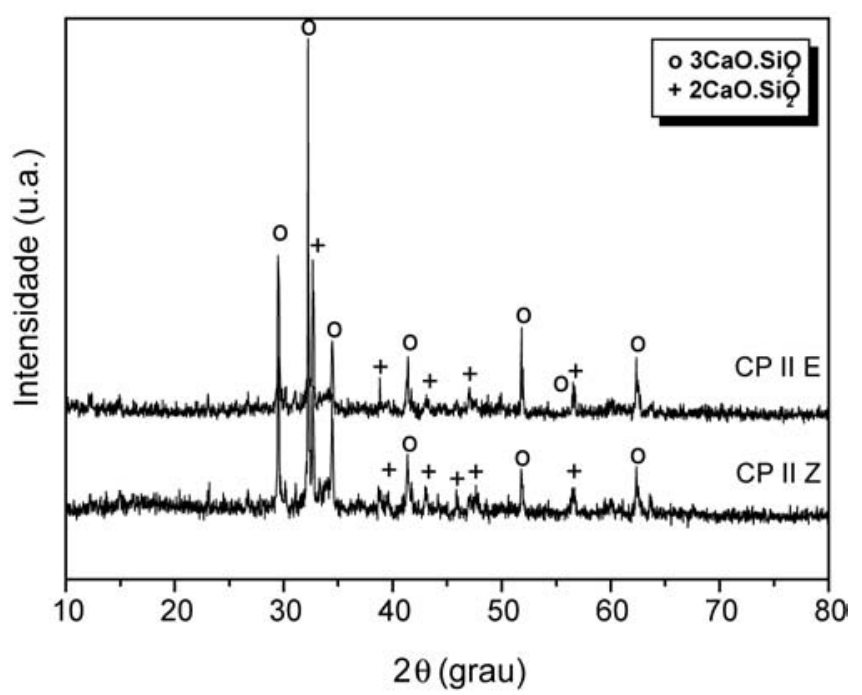

Figura 2: Difratogramas de raios $\mathrm{X}$ dos cimentos Portland CP II Z 32 RS e CP II E 32, ambos da marca Itaú.

[Figure 2: X-ray diffractograms of CP II Z 32 RS and CP II E 32 Portland cements (tradename: Itaú).]

sem valor ou com pouco valor como aglomerante, mas que finamente divididos, em presença de umidade, reagem com o hidróxido de cálcio liberado na hidratação do cimento, e formam compostos compropriedades aglomerantes. Ocimento Portland CP II do tipo $\mathbf{E}$ - como o utilizado - caracteriza-se por possuir os seguintes teores de componentes ( $\%$ em massa): i) Clínquer + sulfatos de cálcio $=56-94$, ii) escoria granulada de alto forno $=6-34$ e iii) material carbonático $=0-10$.

Na Fig. 3 são apresentadas as curvas de distribuição de tamanho de partículas dos cimentos Portland utilizados. As duas curvas fornecem tamanhos médios de partículas

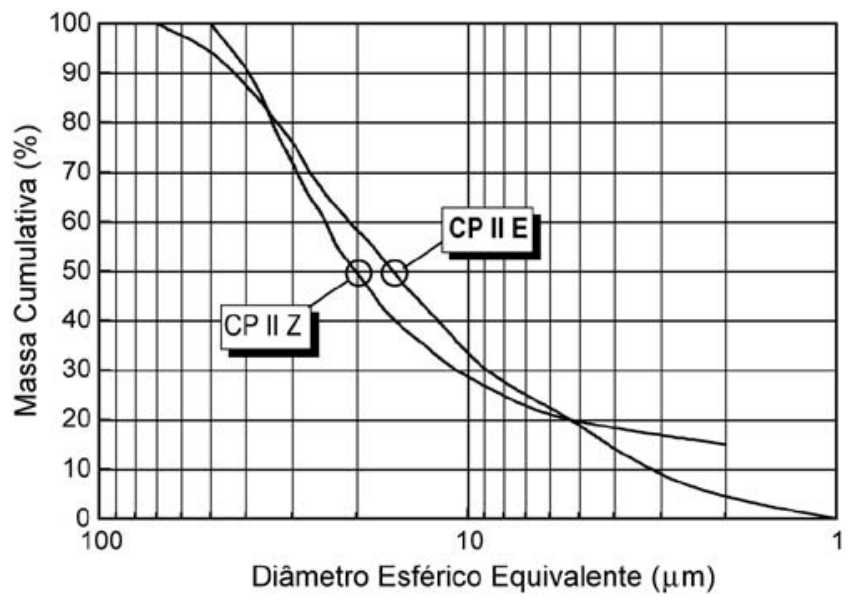

Figura 3: Curva de distribuição de tamanho de partículas para o pó do cimento Portland CP II, da marca Itaú.

[Figure 3: Particle size distribution curves of CP II Portland cement powder (Itaú).] 
próximos, observados através do valor de $50 \%$ da massa cumulativa ( $\sim 20 \mu \mathrm{m}$ para o cimento Portland do tipo $\mathbf{Z}$ e $\approx 17 \mu \mathrm{m}$ para o cimento Portland do tipo E) e ambos possuem uma distribuição um pouco estreita, garantindo uma maior velocidade de reação com a água.

A taxa de reatividade e, portanto, de desenvolvimento da resistência aumenta com quantidades de partículas menores do cimento. Para finalidade de controle industrial, considerase geralmente que partículas de cimento maiores do que 45 $\mu \mathrm{m}$ são difíceis de hidratar e aquelas maiores do que $75 \mu \mathrm{m}$ nunca se hidratam completamente.

Tabela I - Características físicas dos cimentos Portland dos tipos $\mathbf{Z}$ e $\mathbf{E}$.

[Table I - Physical characteristics of the $\mathbf{Z}$ and $\mathbf{E}$ type Portland cements.]

\begin{tabular}{ccc}
\hline Propriedade & Quantificação & $\begin{array}{c}\text { Quantificação } \\
\text { CP II E }\end{array}$ \\
\hline Aparência & Pó cinza claro & Pó cinza claro \\
Densidade real & $3,18 \mathrm{~g} / \mathrm{cm}^{3}$ & $3,02 \mathrm{~g} / \mathrm{cm}^{3}$ \\
Área superficial & & \\
específica & $3,15 \mathrm{~m}^{2} / \mathrm{g}$ & $1,94 \mathrm{~m}^{2} / \mathrm{g}$ \\
$\mathrm{pH}$ & 12,738 & 13,276 \\
\hline
\end{tabular}

$\mathrm{Na}$ Tabela I são apresentados alguns resultados da caracterização dos cimentos utilizados. Através da Tabela I, pode-se observar que as densidades e as áreas superficiais específicas dos cimentos Portland são maiores se comparadas às da areia e da brita, principalmente o cimento Portland CP II Z (Areia: densidade real $=2,74 \mathrm{~g} / \mathrm{cm}^{3}$ e área superficial específica $=1,95 \mathrm{~m}^{2} / \mathrm{g}$; Brita: densidade aparente $=2,73 \mathrm{~g} /$ $\mathrm{cm}^{3} \mathrm{e}$ área superficial específica $=1,46 \mathrm{~m}^{2} / \mathrm{g}$ ). Fato este que, minimiza o problema da correta seleção da proporção e do tamanho adequado dos materiais particulados, fazendo com que os vazios maiores sejam preenchidos com partículas menores, propriedade esta, associada ao empacotamento.

No entanto, o cimento Portland do tipo $\mathbf{E}$ apresenta uma

Tabela II - Desvio padrão referente a resistência à compressão axial para amostras de concretos com utilização de cimentos Portland tipo II E: Média 1 e tipo II Z: Média 2, após 28 dias de cura à $23{ }^{\circ} \mathrm{C}$ e umidade relativa acima de $95 \%$.

[Table II: Standard deviation of axial compressive strength of samples of concrete using type II $\mathbf{E}$ Portland cement: Average 1 and Portland cement $\mathbf{Z}$ : Average 2, after 28 days of aging at $23^{\circ} \mathrm{C}$ and relative humidity exceeding $95 \%$.]

\begin{tabular}{cc}
\hline Tipo de Cimento & Desvio Padrão (MPa) \\
\hline$C P$ II E & 5,23 \\
$C P$ II $Z$ & 2,19 \\
\hline
\end{tabular}

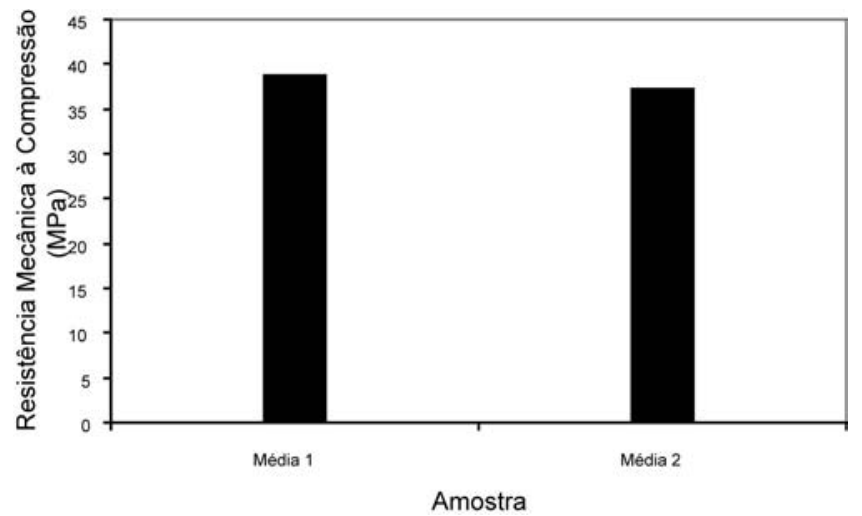

Figura 4: Resistência à compressão axial para amostras de concretos com utilização de cimentos Portland tipo II E: Média 1 e tipo II Z: Média 2, após 28 dias de cura à $23{ }^{\circ} \mathrm{C}$ e umidade relativa acima de $95 \%$.

[Figure 4: Compressive strength of samples of concrete using type II $\mathbf{E}$ Portland cement: Average 1 and Portland cement $\mathbf{Z}$ : Average 2, after 28 days of aging at $23^{\circ} \mathrm{C}$ and relative humidity exceeding 95\%.]

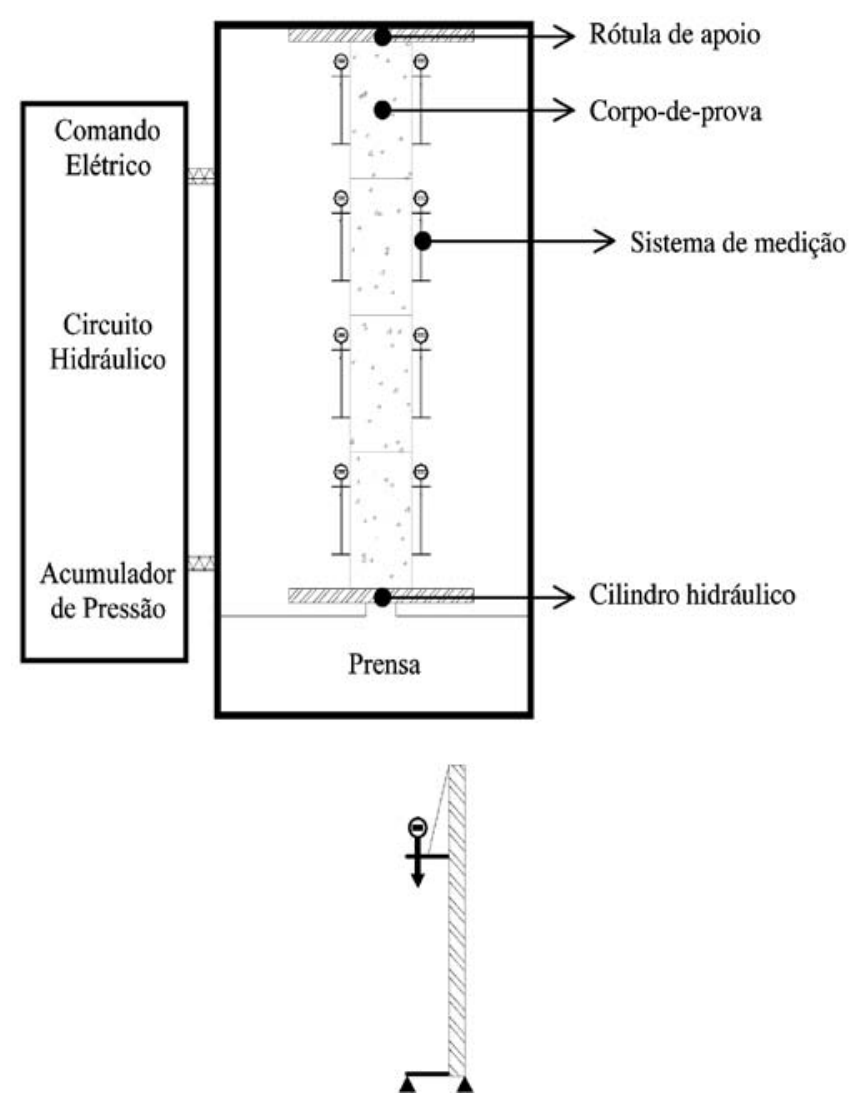

Figura 5: Desenhos esquemáticos do (A) equipamento hidráulico para a realização da fluência em argamassas e concretos e da (B) mesa para medição dos corpos-de-prova de controle (que permanecerão descarregados e que indicarão as variações volumétricas devidas a outras causas, diferentes do carregamento).

[Figure 5: Diagram of the concrete creep hydraulic equipment: (A) creep test machine, and (B) table for measuring nonloaded control specimens.] 
área superficial específica menor do que o cimento Portland do tipo $\mathbf{Z}$ (cerca de $36 \%$ ), mesmo tendo um tamanho médio de partículas menor. Isto se dá, provavelmente, devido à quantidade de partículas maiores do que o valor médio.

Na Fig. 4 e na Tabela II estão mostrados o comportamento do concreto com a utilização de cimentos Portland dos tipos $\mathbf{E}$ e $\mathbf{Z}$, e os desvios padrões, respectivamente.

É possível observar, na Fig. 4, que a amostra de concreto com cimento Portland do tipo $\mathbf{E}$ possui resistência mecânica pouco superior à amostra de concreto com cimento Portland do tipo $\mathbf{Z}(\cong$ $4,5 \%$ ), porém possui um desvio padrão maior (@140\%).

Esquematicamente o projeto para a construção de equipamento específico e da mesa para medição de fluência, se resumiam nos desenhos esquemáticos da Fig. 5.

Nas Figs. 6-8 estão apresentados ensaios da propriedade fluência, para os primeiros oitenta e quatro dias, para composições que se diferenciam no tipo de cimento Portland (CPII Z 32 e CPII E 32). Cada ensaio é feito com 04 corpos-de-prova ao

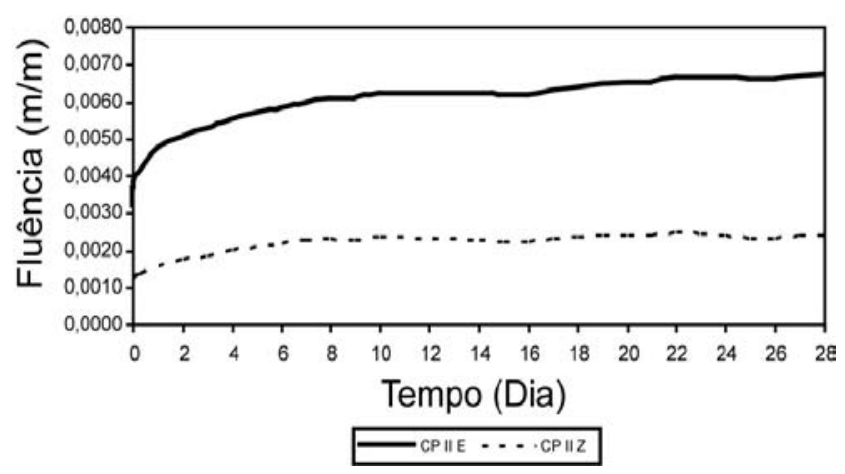

Figura 6: Média da fluência em função da idade de carregamento, com medidas de deformação através de apalpadores óticos, para concretos convencionais, com utilização de cimentos Portland tipo II E: Média 1 e tipo II Z: Média 2.

[Figure 6: Average creep as a function of age. Deformation acquired by optical measurement system.]

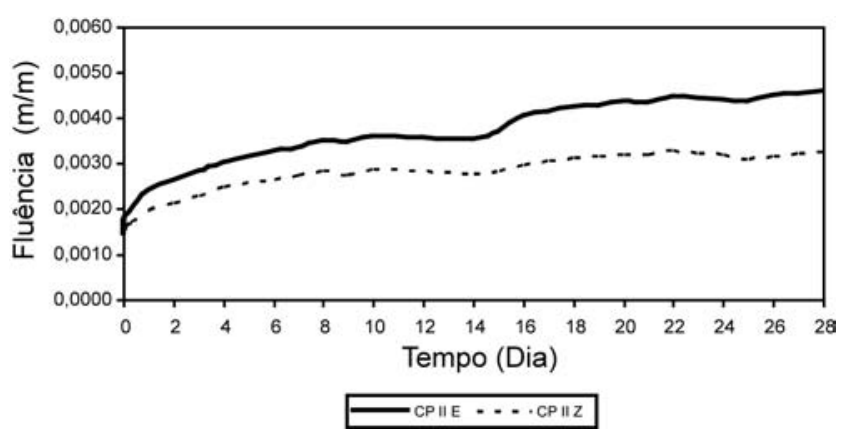

Figura 7: Média da fluência em função da idade de carregamento, com medidas de deformação através de relógios comparadores, para concretos convencionais, com utilização de cimentos Portland tipo II E: Média 1 e tipo II Z: Média 2.

[Figure 7: Average creep as a function of age. Deformation acquired by gauge system.]

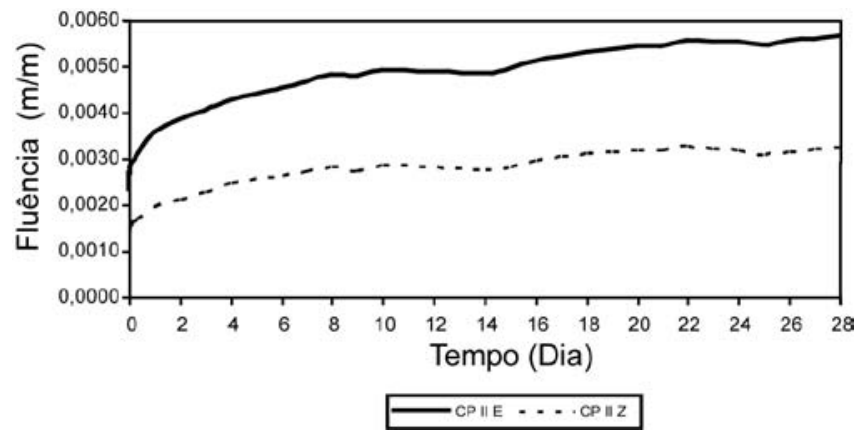

Figura 8: Fluência em função da idade de carregamento, com medidas de deformação através da média de apalpadores óticos e relógios comparadores em diferentes pontos do corpo-de-prova, para concretos convencionais, com utilização de cimentos Portland tipo II $\mathbf{E}$ e tipo II $\mathbf{Z}$.

[Figure 8: Average creep as a function of age. Deformation acquired by both optical and gauge systems]

mesmo tempo e duas composições diferentes. A medida de deformação se baseou na leitura de dois relógios comparadores e um apalpador ótico linear para cada corpo-de-prova.

É possível observar na Fig. 6, média analisada através dos apalpadores, que, a fluência específica (razão do deslocamento medido pelo referencial de espaço deslocado) dos concretos com cimento Portland do tipo $\mathbf{Z}$ é menor em relação aos concretos com cimento Portland do tipo E.

Na Fig. 7 são apresentadas as duas médias analisadas através de relógios comparadores, em relação as duas composições. As curvas não apresentam diferenças significativas, apesar da fluência específica na utilização de cimento Portland do tipo $\mathbf{Z}$ ser um pouco menor.

Na Fig. 8 é apresenta a média das medidas de deformação através da leitura de apalpadores óticos e relógios comparadores. É possível observar que a utilização de cimento Portland do tipo $\mathbf{Z}$ se apresenta como uma melhor alternativa para a confecção de concretos, quando se tratar da propriedade de fluência específica, e se desejar menor deformabilidade.

\section{CONCLUSÕES}

Para as condições utilizadas em todos os ensaios, os resultados foram pertinentes ao que a literatura e a normalização expõem. A utilização de concretos com tipos diferentes de cimentos Portland (E e $\mathbf{Z})$ utilizandose de equipamento específico para medição da propriedade fluência mostrou-se promissor.

Os resultados mostraram que é possível obter concretos para finalidades específicas, somente diferenciando o tipo de cimento Portland utilizado, estabelecendo assim, um melhor controle microestrutural para elaboração de composições a serem estudadas quanto a um controle macroestrutural através da fluência como propriedade.

Em relação ao equipamento, a sua idealização e projeto foram concluídos com êxito e ele se apresenta como mais 
uma nova ferramenta para o estudo específico da propriedade fluência em argamassas e concretos.

\section{AGRADECIMENTOS}

Os autores do presente trabalho agradecem à Fundação de Amparo à Pesquisa do Estado de S. Paulo - FAPESP (processo n. ${ }^{\circ} 02 / 03749-8$ ).

\section{REFERÊNCIAS}

[1] P. Acker, F. J. ULM, "Nuclear engineering and design", Cambridge 203 (2001) 143.

[2] C. Abdunur, P. Acker, B. Miao, IABSE Symposium on durability of structures, Lisbon, Portugal (1989).

[3] T. C. Powers, L. E. Copeland, H. M. Mann, J. Portland Cem. Assoc. Res. Dev. Lab. 2 (1959) 38.

[4] G. J. Verbeck, ASTM Special Tech Publ. 169A (1982) 211.

[5] P. Acker, Z. P. Bazant, J. C. Chem, C. Huet, F. H. Wittmann, Mater. Struct. 31, 212 (1998) 507.

[6] G. E. Troxell, J. E. Raphael, R. W. Davis, ASTM 58 (1958) 1101.

[7] R. G. L'hermite, M. Mamillian, C. Lefèvre, Ann. Inst. Techn. Bâtim. Trav. 18 (1965) 207.
[8] T. C. Hansen, A. H. Mattock, ASCE J. Eng. Mech. 11 (1966) 1261.

[9] A. M. Neville, W. H. Dilger, J. J. Brooks, Construction Press (1983).

[10] Z. P. Bazant, Wiley 20, (1988) 395.

[11] P. K. Mehta, P. J. M. Monteiro, "Concreto, estrutura, propriedades e materiais", S. Paulo: PINI (1994).

[12] A. M. Neville, Appl. Sci. Res. 44 (1960) 285.

[13] M. M. Smadi, F. O. Slate, ACl Mater. J. 86, 2 (1989) 117.

[14] L. L. Yue, L. Taerwe, Mag. Concr. Res. 44, 161 (1992) 281.

[15] A. M. Neville, H. W. Kenington, Symposium on the chemistry of cement, Washington DC, EUA (1960) 703.

[16] A. M. Neville, J. Prestressed Concr. Inst. (1958).

[17] G. E Troxell, J. M. Raphel, R. E. Davis, ASTM 58 (1958) 1101.

[18] A. M. Neville, RILEM Bill. 4 (1959) 5.

[19] F. H Wittman, P. E Roelfstra, Cem. Conc. Res. 10, 5 (1980) 601.

[20] P. Rossi, P. Acker, Cem. Concr. Res. 18, 5 (1988) 799.

[21] ABNT - MB-1: "Cimento Portland - Determinação da resistência à compressão", Rio de Janeiro (1991).

[22] ABNT - NBR 8224, "Concreto endurecido Determinação da fluência”, Rio de Janeiro (1983).

[23] ABNT - NBR 5737, "Cimento Portland resistente aos sulfatos", Rio de Janeiro (1992).

(Rec. 10/02/2005, Ac. 30/09/2005) 